\title{
Gamificação no Ensino de Programação de Computadores em turmas do Ensino Médio: uma experiência com o software Kahoot!
}

\author{
Jamille Silva Madureira - Instituto Federal de Sergipe - \\ jamille.madureira@ifs.edu.br - https://orcid.org/0000-0003-2145-4637 \\ Henrique Nou Schneider - Universidade Federal de Sergipe - \\ hns@terra.com.br - https://orcid.org/0000-0003-2354-576X
}

\begin{abstract}
Resumo: Há diversos motivos que tornam a aprendizagem de programação de computadores um processo árduo, ao qual as abordagens de ensino tradicionais não têm conseguido responder de forma satisfatória. As dificuldades foram ressaltadas no ensino remoto emergencial, pois os estudantes passaram a desenvolver suas atividades sozinhos em suas residências. Assim, a fim de mobilizar os estudantes e favorecer a aprendizagem nesse novo modelo de ensino, a estratégia da gamificação foi adotada como parte integrante da metodologia. Foram desenvolvidos jogos por meio do software Kahoot! com os conteúdos abordados nas aulas. Os resultados evidenciam que a gamificação desenvolveu a motivação nos estudantes, ao incentivar a revisão dos conteúdos e por ser uma maneira lúdica para avaliar a aprendizagem.
\end{abstract}

Palavras-chave: Scratch. Algoritmos. Ensino Remoto Emergencial. Metodologias Ativas.

\section{Gamification in Teaching Computer Programming in High School classes: an experience with Kahoot! software}

\begin{abstract}
There are several reasons that make learning computer programming an arduous process, to which traditional teaching approaches have not been able to respond satisfactorily. Difficulties were highlighted in emergency remote teaching, as students started to develop their activities alone in their homes. Thus, in order to mobilize students and favor learning in this new teaching model, the gamification strategy was adopted as an integral part of the methodology. Games were developed using Kahoot! with the contents covered in the classes. The results show that gamification has developed motivation in students, by encouraging the review of content and for being a ludic way to assess learning.
\end{abstract}

Keywords: Scratch. Algorithms. Emergency Remote Learning. Active Methodologies

\section{Introdução}

O ensino de programação de computadores tem como objetivo capacitar os estudantes no desenvolvimento de um conjunto de competências necessárias para conceber programas que resolvam problemas reais. No entanto, a experiência tem indicado que existe uma grande dificuldade em compreender e aplicar os conceitos abstratos de programação, devido à complexidade do assunto, dos estereótipos associados e da ausência do estímulo adequado ao aprendizado do discente (SILVA, T et al., 2021)

Além disso, nas turmas as quais esta pesquisa foi desenvolvida, já era comum os estudantes apresentarem dificuldades de adaptação do Ensino Fundamental para o Ensino Médio, principalmente em razão da grande carga de disciplinas. Isso acontece porque, além das disciplinas regulares do Ensino Médio, são acrescentadas aquelas do núcleo profissionalizante, totalizando quinze componentes curriculares distribuídos em trinta e três horas-aula semanais. 
Essas adversidades foram evidenciadas durante o ensino remoto emergencial adotado em consequência da pandemia da COVID-19, pois as aulas passaram do mundo físico ao ciberespaço. Nesse contexto, cada vez mais tem se pensado em estratégias que possam auxiliar na execução de atividades educacionais. As Tecnologias Digitais de Informação e Comunicação (TDIC) têm contribuído para dar continuidade às atividades de ensino e manter o vínculo entre o professor, estudantes e a instituição (SONEGO, SILVA e BEHAR, 2021).

Com o objetivo de tornar lúdico o ensino, os jogos educacionais têm sido aplicados como técnicas de aprendizagem ativa. A gamificação proporciona o aumento de engajamento dos estudantes, visto que estão alinhados ao estilo de aprendizagem das gerações atuais (CLASSE e CASTRO, 2020). Com esse propósito, na disciplina Informática Básica, foi incluída a gamificação por meio de jogos na plataforma Kahoot!.

Assim, este artigo tem por objetivo apresentar os resultados de uma pesquisa ${ }^{1}$ qualitativa que analisou a adoção da metodologia da gamificação no ensino de programação de computadores em duas turmas do primeiro ano do Ensino Médio Integrado ao Técnico de dois cursos do Instituto Federal de Sergipe, campus Estância.

O artigo encontra-se estruturado da seguinte maneira: na seção 2 são apresentadas a metodologia, o campo empírico e os sujeitos da pesquisa; na seção 3 são demonstrados os resultados obtidos e, por fim, na seção 4, são feitas as considerações finais.

\section{Metodologia, campo empírico e sujeitos da pesquisa}

\section{1 - Caminho metodológico}

A pesquisa realizada é de natureza qualitativa e teve como objetivo experenciar a adoção da estratégia gamificação no processo ensino-aprendizagem de programação de computadores em turmas do primeiro ano do Ensino Médio. O procedimento metodológico adotado foi um estudo de caso, por meio da observação participante e da entrevista semiestruturada.

Com o objetivo de coletar os dados da pesquisa, um questionário online foi aplicado por meio do dispositivo Google Forms, com perguntas sobre a experiência do uso do Kahoot! durante a disciplina.

Para realizar a análise qualitativa dos resultados, foi aplicado o método ATD (Análise Textual Discursiva), descrito por Moraes e Galiazzi (2016). O método é composto por três fases: unitarização, categorização e meta-textos analíticos. Na etapa da unitarização, os textos são separados em unidades de significado. Na interpretação do significado atribuído pelos autores, destaca-se as palavras dos participantes para compreender melhor o texto. A categorização consiste na articulação de significados semelhantes, podendo gerar vários níveis de categorias de análise. Este processo gerou meta-textos analíticos que constituíram os textos interpretativos, ou seja, os resultados da pesquisa apresentados na Seção 3.

\footnotetext{
${ }^{1}$ Pesquisa resultante do Projeto de Pesquisa Externo Gamificação no Processo Ensino-Aprendizagem Remoto Emergencial: estudo de caso no Ensino Fundamental das Séries Iniciais e no Ensino Médio, usando o software Kahoot! submetido ao Departamento de Computação da Universidade Federal de Sergipe (PEB9719-2020).
} 


\section{2 - Campo empírico e sujeitos da pesquisa}

Elegeu-se duas turmas do primeiro ano do Ensino Médio Integrado ao Técnico do Instituto Federal de Sergipe, campus Estância, como campo empírico.

No total, 61 discentes participaram da pesquisa, sendo 26 do curso de Edificações ( 9 do sexo masculino e 17 do sexo feminino) e 35 do curso de Eletrotécnica ( 20 do sexo masculino e 15 do sexo feminino).

Os jogos abordaram os conteúdos de programação de computadores com a linguagem Scratch, uma linguagem gráfica de programação de fácil manuseio e intuitiva. Esta linguagem possibilita ao aprendiz praticar o raciocínio lógico e realizar a programação de maneira lúdica e criativa, além de compartilhar suas experiências, o que também é fundamental para as competências esperadas dos profissionais atuais (VENTURA, BIANCHINI e KIRNEW, 2019).

Os conteúdos da disciplina Informática Básica foram revisados em quatros jogos, um por bimestre, disponibilizados aos sábados letivos, distribuídos conforme a Tabela 1.

Tabela 1 - Conteúdos dos jogos

\begin{tabular}{|c|c|c|c|}
\hline \multirow{2}{*}{$\begin{array}{r}\text { Mês / Ano } \\
\text { Outubro/2020 }\end{array}$} & Conteúdo & Descrição & Competências \\
\hline & $\begin{array}{l}\text { Movimento de } \\
\text { sprites no } \\
\text { palco. }\end{array}$ & $\begin{array}{l}\text { Realização de } \\
\text { operaçóes } \\
\text { matemáticas na } \\
\text { linguagem Scratch. } \\
\text { Direcionamento de } \\
\text { sprites no ambiente. }\end{array}$ & $\begin{array}{l}\text { Conhecer outros operadores } \\
\text { como: resto de divisão, teto, } \\
\text { piso e arredondamento. } \\
\text { Compreender a ordem de } \\
\text { prioridade entre os operadores. } \\
\text { Revisar o plano cartesiano por } \\
\text { meio de movimentações do } \\
\text { sprite em quatro direções (cima, } \\
\text { baixo, esquerda e direita). }\end{array}$ \\
\hline Novembro/2020 & $\begin{array}{l}\text { Algoritmos } \\
\text { sequenciais. }\end{array}$ & $\begin{array}{l}\text { Solução de } \\
\text { problemas por meio } \\
\text { de algoritmos. }\end{array}$ & $\begin{array}{l}\text { Identificar soluções algorítmicas } \\
\text { para problemas matemáticos. } \\
\text { Reconhecer os elementos de } \\
\text { algoritmos: entrada, } \\
\text { processamento e saída. }\end{array}$ \\
\hline Janeiro/2021 & $\begin{array}{l}\text { Operadores } \\
\text { relacionais e } \\
\text { lógicos. } \\
\text { Estrutura } \\
\text { condicional. }\end{array}$ & $\begin{array}{l}\text { Solução de } \\
\text { problemas por meio } \\
\text { de algoritmos } \\
\text { condicionais. }\end{array}$ & $\begin{array}{l}\text { Conhecer os operadores } \\
\text { relacionais e lógicos e suas } \\
\text { aplicações nas estruturas de } \\
\text { decisão em algoritmos. }\end{array}$ \\
\hline Março/2021 & Broadcast. & $\begin{array}{l}\text { Troca de mensagens } \\
\text { entre sprites. }\end{array}$ & $\begin{array}{l}\text { Compreender o funcionamento } \\
\text { de broadcast e suas aplicações } \\
\text { em projetos. }\end{array}$ \\
\hline
\end{tabular}




\section{3 - A estratégia gamificação}

A gamificação é definida como a utilização de mecânica, estética e pensamento baseados em games com o objetivo de engajar pessoas, promover a aprendizagem e resolver problemas (KAPP, 2013).

Apesar de que esse termo tenha sido empregado pela primeira vez em 2010, a gamificação tem sido aplicada há muito tempo. Um exemplo é na educação, quando a criança podia ter seu trabalho reconhecido com estrelinhas, caracterizando uma recompensa, ou aumentar gradativamente a dificuldade de soletrar as palavras durante o ditado, tendo assim os níveis adaptados às habilidades dos usuários (FADEL,2014).

Aplicando os conceitos de gamificação, o aprendizado se torna mais eficaz, tornando o ambiente colaborativo, pois a maioria das soluções gamificadas encoraja os aprendizes a desenvolverem uma rede de colegas ou contar com a ajuda de um tutor para estimular o processo (BURKE, 2015).

Fundamentar a aprendizagem em games pressupõe a construção de um sistema no qual os aprendizes estarão engajados em "um desafio abstrato, definido por regras claras, interagindo e aceitando feedback com o alcance de resultados quantificáveis e com a presença de reações emocionais" (ALVES, 2015, p.27).

Com o objetivo de aplicar a gamificação nesta pesquisa, os jogos foram desenvolvidos no Kahoot!, um software interativo que incorpora elementos utilizados no design dos jogos para proporcionar o engajamento dos usuários na aprendizagem, dentro e fora das salas de aula.

Os jogos possuem o formato de quiz, que são questionários de múltipla escolha e permitem avaliar dando um feedback rápido ao jogador, visto que a correção é automática. Ao final de cada atividade, o dispositivo disponibiliza, ao professor, um relatório geral do desempenho, apresentando como as perguntas foram respondidas (corretas e erradas) e ainda o tempo de resposta que cada estudante utilizou (SILVA, J. et al., 2018).

Na Seção 3 estão apresentados, com mais detalhes, os jogos aplicados e os resultados obtidos nesta pesquisa.

\section{Resultados}

Esta pesquisa aconteceu entre os meses de agosto de 2020 a julho de 2021 e contou com a participação de 61 estudantes ingressantes do Ensino Médio Integrado ao Técnico do Instituto Federal de Sergipe, campus Estância.

Devido à pandemia da Covid-19, as aulas aconteceram exclusivamente no ciberespaço. A plataforma adotada para auxiliar neste processo foi a Google for Education, sendo os recursos mais utilizados o Google Classroom, Google Forms e o Google Meet. Este último foi utilizado para os momentos síncronos das aulas, nos quais os estudantes receberam as orientações dos conceitos de programação e da linguagem Scratch. Com o objetivo de auxiliar os estudantes com dificuldade de conexão à internet, foi criado um canal no Youtube para disponibilização de vídeos sobre os conteúdos, sendo estes de curta duração.

A plataforma Scratch foi escolhida para o ensino de programação de computadores, pois esta possibilita ao estudante concentrar-se no raciocínio lógico para resolver problemas, não precisando se preocupar com erros de sintaxe no ato de programar o computador, muito comuns durante a aprendizagem. Outra vantagem são os recursos audiovisuais, propiciando o uso da criatividade no desenvolvimento dos projetos. 
Com o objetivo de aplicar a metodologia ativa da gamificação, os conteúdos da disciplina Informática Básica foram revisados em quatros jogos, um por bimestre, conforme descrito na Tabela 1. Como parte da avaliação, os estudantes que responderam aos jogos somavam um ponto extra no referido bimestre.

Os jogos foram elaborados na plataforma Kahoot! e abordaram programação de algoritmos na linguagem Scratch. Com o propósito de utilizar os recursos oferecidos pelo software, foram aplicados diversos tipos de perguntas, tais como: figuras nas questões e respostas, verdadeiro e falso, realização de cálculos aritméticos e respostas textuais.

$\mathrm{O}$ formato de jogo adotado foi o Challenge, um desafio no qual os estudantes tiveram um prazo para responder o quiz e, ao finalizar, o Kahoot! gera um relatório com os dados das respostas. Também é gerado um pódio com os três primeiros lugares na competição. Em cada desafio, foi dado o tempo limite de uma semana de acesso, assim, os aprendizes teriam tempo suficiente para respondê-lo.

Exemplos de questões podem ser observadas na Figura 1, nas quais os discentes deveriam interpretar algoritmos (Figura 1(a)), indicar qual comando utilizar para obter um determinado resultado (Figura 1(b)), avaliar expressões matemáticas (Figura (1c)) e também afirmações como Verdadeira ou Falsa (Figura (1d)).

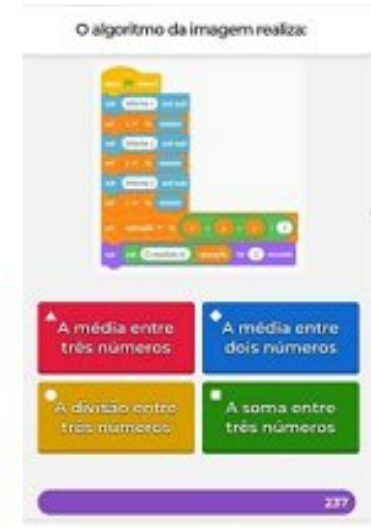

(a)

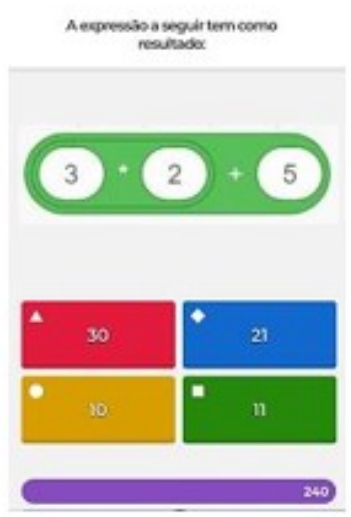

(c)

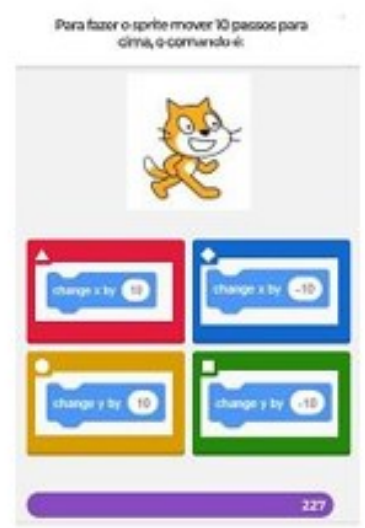

(b)

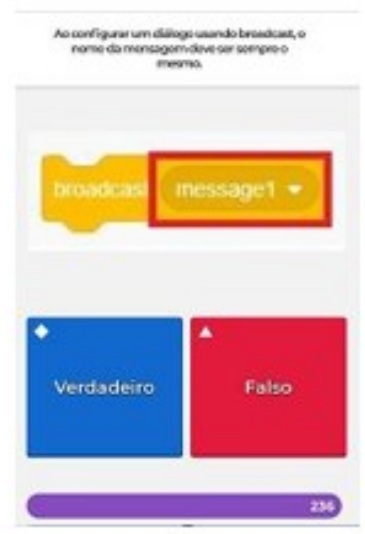

(d)

Figura 1 - Questões aplicadas nos jogos

No final do ano letivo, foi aplicado um questionário online nas turmas utilizando o software Google Forms, com oito perguntas objetivas sobre a adoção da gamificação por meio da Kahoot! na disciplina e uma pergunta dissertativa, para que o estudante 
pudesse registrar livremente suas opiniões. Com o objetivo de garantir a confidencialidade das respostas, a identificação não foi obrigatória.

Após a extração e identificação das unidades de significado obtidas pelo questionário, estas foram categorizadas pelos seus sentidos, de acordo com o método ATD (MORAES; GALIAZZI, 2016). Assim, foram identificadas cinco categorias iniciais, três intermediárias e uma final, como mostrado na Tabela 2.

Tabela 2 - Categorias

\begin{tabular}{|l|l|l|}
\hline Categorias iniciais & Categorias intermediárias & Categoria Final \\
\cline { 1 - 2 } Aprendizagem & Ensino-aprendizagem (A) & $\begin{array}{l}\text { Ensino-aprendizagem } \\
\text { comunicacional }\end{array}$ \\
\cline { 1 - 2 } Avaliação & & \\
\cline { 1 - 2 } Gamificação & Kahoot! (B) & \\
\cline { 1 - 2 } Kahoot! & Comunicação (C) & \\
\cline { 1 - 2 } & &
\end{tabular}

A categoria intermediária Ensino-aprendizagem(A) foi composta pelas categorias iniciais Aprendizagem, Avaliação e Gamificação. Os discentes destacaram que o Kahoot! contribuiu para a aprendizagem na disciplina Informática Básica durante o ensino remoto por ser uma forma divertida de revisar os conteúdos e testar os conhecimentos.

Os jogos exigiam um raciocínio rápido para responder as questões antes do tempo determinado, assim como para obter mais pontos, pois quanto menor o tempo para responder, maior a pontuação obtida. Os estudantes também relataram que foi motivador competir com os colegas, visto que ao final de cada jogo um pódio era exibido com as pontuações dos três primeiros lugares, como pode ser observado na Figura 2, aumentando a interação entre a turma. Outro ponto destacado foi o incentivo para a revisão dos assuntos antes de responder, para que tivessem um bom desempenho no game.

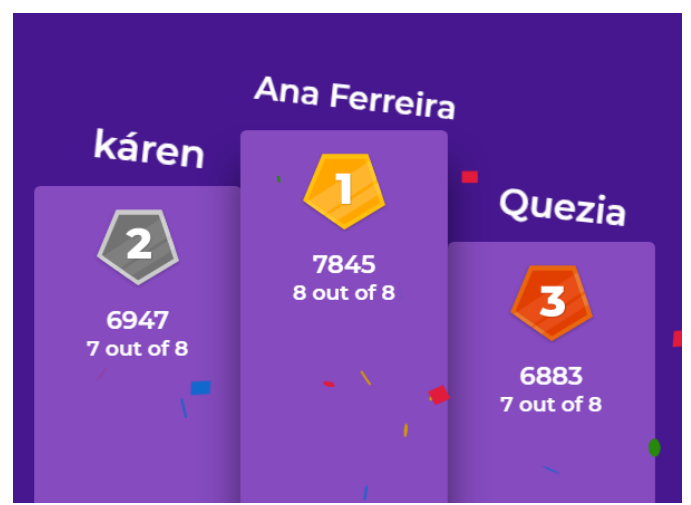

Figura 2 - Pódio gerado em um dos desafios

Assim, foi observado que no decorrer do ensino remoto emergencial, a adoção da gamificação motivou os estudantes, demonstrando que o uso de metodologias ativas de ensino e aprendizagem pode abrir portas a um maior engajamento dos discentes como protagonistas deste processo.

Quanto à categoria Kahoot!(B), esta surgiu por ser o software adotado nesta pesquisa, com o objetivo de aplicar a gamificação como metodologia ativa durante o ensino remoto. Os estudantes participantes afirmaram que foi uma forma divertida de aprender, e os relatórios disponibilizados para o professor colaboram para que este possa identificar as dificuldades que os estudantes apresentam na sua disciplina, indicando, inclusive, quem necessita de um atendimento individualizado. 
Após a finalização do desafio, o Kahoot! gera automaticamente algumas informações que são úteis para o professor avaliar o desempenho da turma. Um exemplo é a seção "Difficult questions" que mostra quais as perguntas tiveram maior índice de erros, o que permite o(a) professor(a) refletir sobre o assunto abordado e/ou a elaboração da pergunta, conforme apresentado na Figura 3.

\begin{tabular}{|c|c|c|c|}
\hline & Difficult questions (2) & & Search \\
\hline \multicolumn{2}{|c|}{ Question $\vee$} & Type $\vee$ & Correct/incorrect $\checkmark$ \\
\hline 8 & Neste código, quando o sprite receber o broadcast: & Quiz & $28 \%$ \\
\hline 5 & O código a seguir executa a seguinte ação quando a bandeira verde é clicada: & Quiz & $34 \%$ \\
\hline
\end{tabular}

Figura 3 - Perguntas com maior índice de erros

Outro recurso disponível para o professor é o "Need Help", que mostra quais estudantes tiveram uma pontuação considerada baixa no jogo, e precisam de ajuda, como pode ser visualizado na Figura 4.

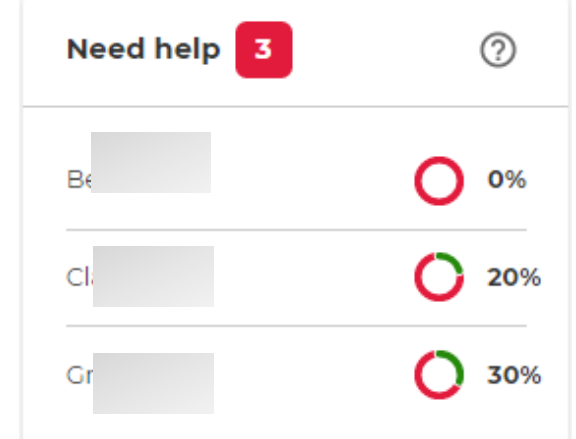

Figura 4 - Estudantes que precisam de ajuda

Ao clicar no nome do estudante, o Kahoot! apresenta todo o seu desempenho, indicando a pontuação, os erros e acertos, assim como quanto tempo levou para responder cada pergunta, conforme observado na Figura 5.

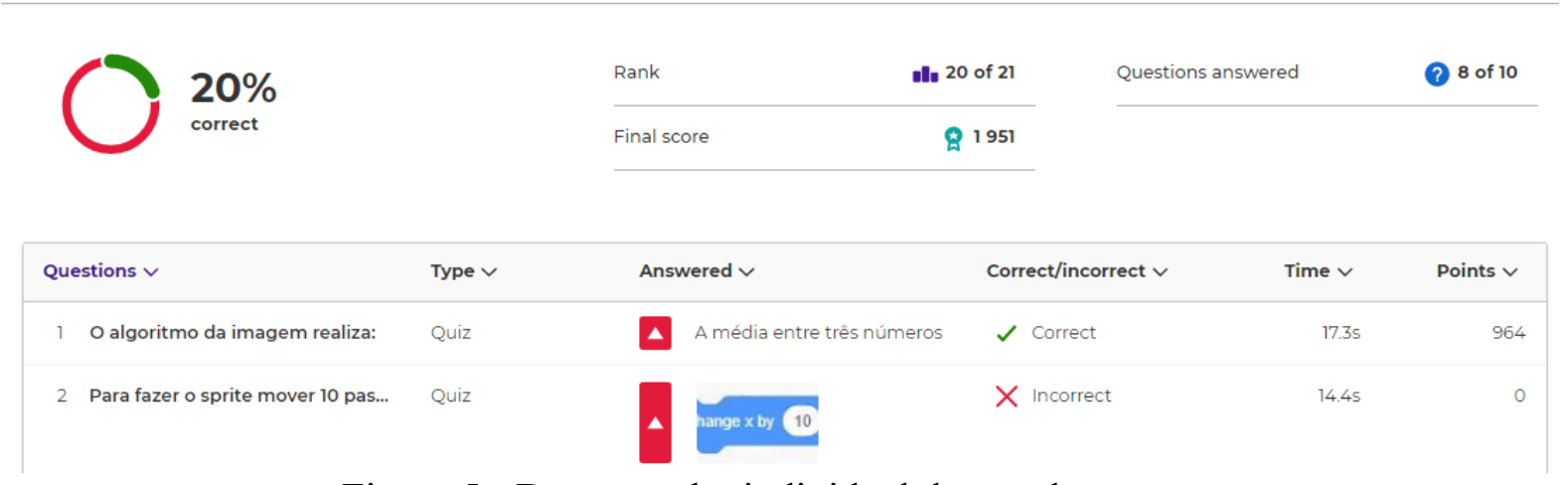

Figura 5 - Desempenho individual do estudante

Para que o professor tenha uma visão do resultado da turma, a programa também apresenta um relatório geral, conforme mostrado na Figura 6, no qual mostra o desempenho individual de cada estudante. 


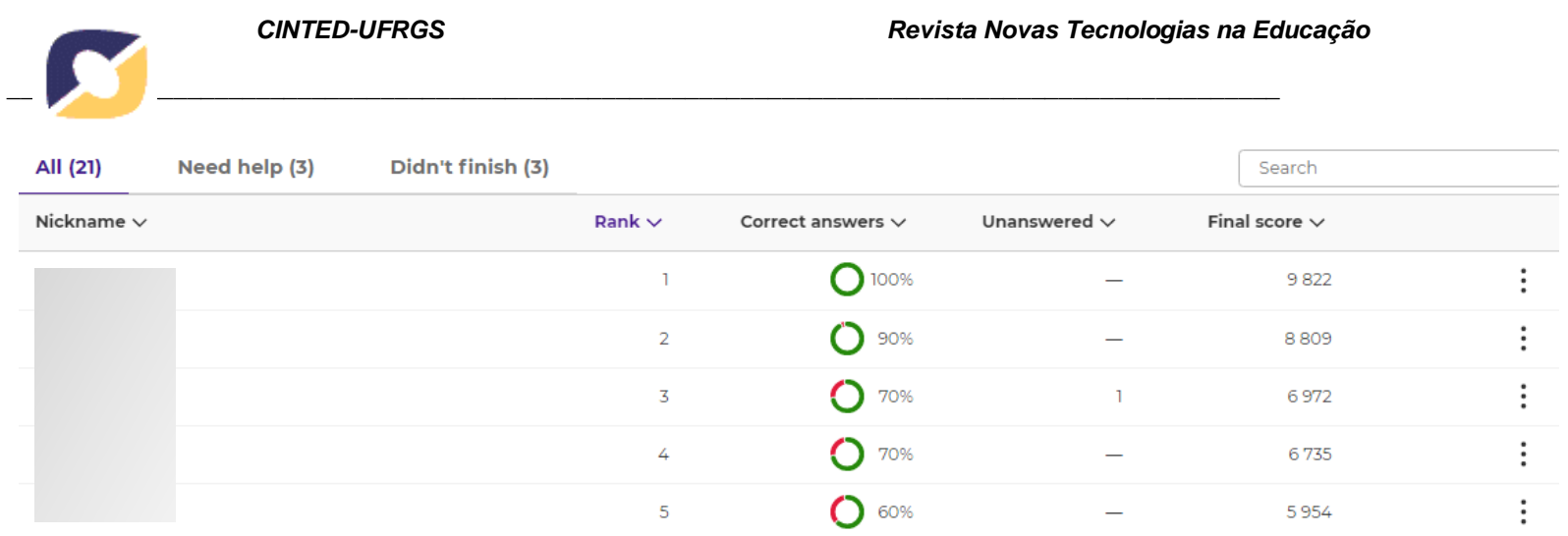

Figura 6 - Desempenho da turma

Os discentes destacaram que o jogo contribuiu para testar os conhecimentos de forma divertida, porém alguns enfrentaram dificuldades por precisar estar conectado à internet para jogar, e nem sempre isso era possível. A conexão com uma internet de baixa qualidade também prejudicou o momento de jogar, pois o tempo disponível para responder às questões foi considerado curto pelos estudantes que se encontraram nessa situação.

Por fim, a categoria intermediária Comunicação (C) destacou-se pelo fato de que, pela primeira vez, devido à pandemia causada pela COVID-19, esta aconteceu exclusivamente no ciberespaço.

A plataforma Google for Education foi adotada pela escola onde esta pesquisa foi realizada, tendo como principais recursos o Google Sala de Aula (postagem de material, entrega de atividades, comunicação assíncrona) e o Google Meet (comunicação síncrona). As instruções dos jogos foram dadas nestas plataformas, com o link do jogo e um tutorial de como jogar. Eventualmente, uma mensagem de texto era passada pelo aplicativo WhatsApp nos grupos das turmas, com o objetivo de lembrar da atividade e o prazo de encerramento.

Desta forma, o Ensino-aprendizagem comunicacional, como categoria final, foi o resultado da adaptação do Ensino-aprendizagem (A) do modo presencial para o remoto, adotando como metodologia ativa a gamificação por meio de jogos no Kahoot!(B), tendo a Comunicação $(\mathrm{C})$ via ciberespaço como principal espaço para a interação entre os professores e estudantes.

Foi um momento desafiador para os aprendizes, que precisaram desenvolver sua autonomia nos estudos, pois tiveram que permanecer sozinhos em suas casas sem a presença dos colegas e professores. As turmas participantes desta pesquisa são ingressantes, e mesmo no ensino presencial, é comum passarem por dificuldades de adaptação do ensino fundamental para o médio integrado técnico. No ensino remoto, as adversidades foram acentuadas, pois além do distanciamento, nem todos os estudantes possuem os recursos técnicos necessários para o bom acompanhamento das atividades, como computadores e uma conexão eficaz com a internet.

Os docentes, por sua vez, tiveram que se adaptar a essa nova forma de ensinar. A instituição ofertou cursos sobre as tecnologias digitais adotadas, mas o cotidiano revelou dificuldades por parte dos professores migrarem suas aulas para o espaço virtual. Além de ter que adaptar o material (apostilas, avaliações, criação e edição de vídeo aula) pensando no estudante que deveria estudar sozinho em casa, também foi preciso aprender novos dispositivos digitais e seus recursos, como, por exemplo, o Kahoot!.

A gamificação mostrou-se uma metodologia adequada para promover a aprendizagem, pois possibilitou aos estudantes motivarem-se nos estudos e incentivou a interação com os colegas. Em ambas as turmas, os aprendizes afirmaram que o Kahoot! é uma forma divertida de aprender, conforme depoimentos na Figura 7. 


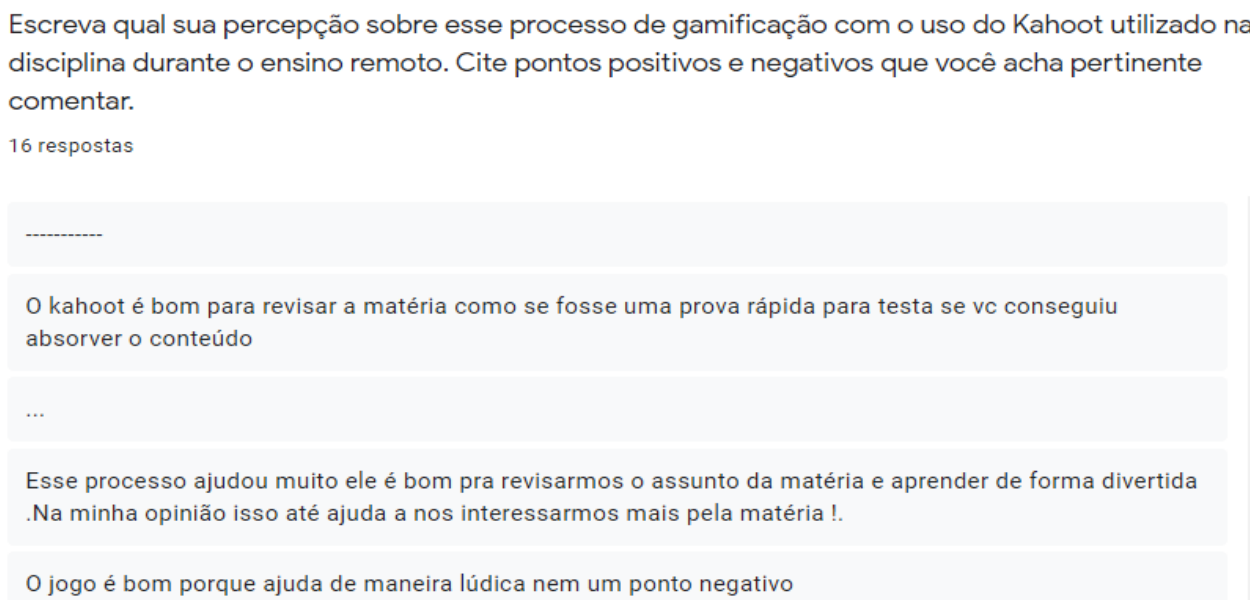

Figura 7 - Depoimentos dos estudantes

\section{Considerações finais}

Esta pesquisa teve como objetivo investigar a adoção da metodologia gamificação por meio de jogos na plataforma Kahoot!. Os discentes participantes foram os ingressos dos cursos de nível Médio Integrado ao Técnico do Instituto Federal de Sergipe.

Com a pandemia causada pela COVID-19, as aulas aconteceram exclusivamente de forma remota, o que trouxe muitos desafios. Por um lado, os discentes, que já sentiam dificuldades de adaptação do ensino fundamental para o ensino médio, principalmente devido à grande carga de disciplinas. Ademais, no ensino remoto, essas adversidades foram acentuadas, pois além do excesso de conteúdo, estes estudantes tiveram que desenvolver a autonomia na aprendizagem, visto que não houve a presença física dos colegas e professores para auxiliá-los nesse processo.

Por outro lado, os professores também enfrentaram adversidades. As aulas tiveram que ser replanejadas para o novo modelo de ensino, considerando que a interação ocorreria apenas no ciberespaço. Assim, tanto o material explicativo do conteúdo (apostilas, videoaulas) foram adaptados, quanto os meios de avaliação. Também foi preciso adotar novas metodologias de ensino-aprendizagem, principalmente com o objetivo de mobilizar os aprendizes na direção das suas motivações, visto que a iminência de abandono era constante.

Outro ponto a se destacar são as dificuldades na aprendizagem da programação de computadores, principalmente por exigir um raciocínio lógico e matemático na elaboração de algoritmos. Por serem turmas do ensino médio, foi adotada a linguagem Scratch, voltada para jovens devido ao seu caráter lúdico e por permitir o desenvolvimento da criatividade em seus projetos.

Assim, com esse propósito, é que na disciplina Informática Básica, foi incluída a gamificação por meio de jogos na plataforma Kahoot!. No final de cada bimestre, um jogo era disponibilizado para as turmas, revisando os conteúdos abordados. Como parte da avaliação, aos estudantes que concluíram os desafios, foi adicionado um ponto extra na sua nota do referido bimestre.

Ao final do processo, os discentes relataram que os jogos foram uma maneira divertida de testar seus conhecimentos, pois exigiam um raciocínio rápido devido ao tempo limitado para responder. Outros afirmaram revisar os assuntos antes de jogar, para ter um bom resultado.

Para o professor, o software Kahoot! é válido, tanto por ser uma nova forma de avaliação da aprendizagem, quanto pelos relatórios gerados. Por meio destes, foi possível 
identificar conteúdos de maior dificuldade de entendimento, assim como os estudantes que precisavam de um acompanhamento individual com objetivo de melhorar o desempenho na disciplina.

Assim, a adoção da gamificação como parte integrante das metodologias durante o ensino remoto foi motivadora para os estudantes, ao incentivar a revisão dos conteúdos e por ser uma maneira divertida de avaliar suas aprendizagens. A experiência mostrou que o Kahoot! facilitou a aprendizagem e, portanto, será adotado nos próximos anos letivos, inclusive no ensino presencial.

\section{Referências}

ALVES , F. Gamification: como criar experiências de aprendizagem engajadoras. 2. ed. São Paulo: DVS, 2015. 200 p. ISBN 8582891024.

BURKE, B. Gamificar: como a gamificação motiva as pessoas a fazerem coisas extraordinárias. São Paulo: DVS, 2015. 192 p. ISBN 8582891075.

CLASSE, T. M. D.; CASTRO, R. M. D. Melhorando o Aproveitamento dos Alunos em Fundamentos de Computação e Sistemas Através de Atividades Lúdicas. RENOTE Revista Novas Tecnologias na Educação, v. 18, n. 1, p. 296-305, Dezembro 2020. ISSN 1679-1916.

FADEL, L. M. et al. Gamificação na Educação. São Paulo: Pimenta Cutural, 2014. ISBN 978-85-66832-13-6.

KAPP, K. M. The gamification of learning and instruction fieldbook: Ideas into practice. 1. ed. San Francisco: Wiley, 2013. ISBN 978-1118674437.

MORAES, R.; GALIAZZI , M. D. C. Análise Textual Discursiva. 3. ed. Ijuí: Unijuí, 2016. 264 p. ISBN 978-8541902175.

SILVA, J. B. D. et al. Tecnologias digitais e metodologias ativas na escola: o contributo do Kahoot para gamificar a sala de aula. Thema, Pelotas, p. 780-791, 2018. ISSN $2177-$ 2894.

SILVA, T. R. D. et al. Um mapeamento sistemático sobre o ensino e aprendizagem de programação. RENOTE - Revista Novas Tecnologias na Educação, v. 19, n. 1, p. 156165, Julho 2021. ISSN 1679-1916.

SONEGO, A. H. S.; SILVA, J. S. D.; BEHAR, P. A. Estratégias pedagógicas no ensino remoto: Possibilidades para diminuir a exclusão digital. RENOTE - Revista Novas Tecnologias na Educação, v. 19, n. 1, p. 62-72, Julho 2021. ISSN 1679-1916.

VENTURA, L. M.; BIANCHINI, L. G. B.; KIRNEW, L. C. P. Scratch e a possibilidade de novos sentidos sobre o ensino da Lógica de Programação. Revista de Estudos e Pesquisas sobre Ensino Tecnológico (EDUCITEC), v. 5, n. 11, p. 73-85, 2019. ISSN 2446-774X. 